\title{
OTIMIZAÇÃO DA MALHA DE AMOSTRAGEM DE COMPOSTOS ORGÂNI- COS VOLÁTEIS NO SOLO ATRAVÉS DE KRIGAGEM
}

\author{
SAMPLING MESH OPTIMIZATION OF VOLATILE ORGANIC COMPOUNDS IN \\ SOIL THROUGH KRIGING
}

Adriana Lemos Portol, José Agnelo Soares²,Veruschka Escarião Dessoles Monteiro

\begin{abstract}
RESUMO
Este trabalho visa apresentar metodologia para otimizar o dimensionamento de uma malha de amostragem de compostos orgânicos voláteis (VOCs) em uma área de armazenamento de hidrocarbonetos derivados de petróleo, com cerca de 20 hectares, de onde foram coletadas 2361 amostras de solo. Em cada ponto foram adquiridas amostras a 0,5 m, 1,0 $\mathrm{m}$ e $1,5 \mathrm{~m}$ de profundidade. A técnica utilizada foi a krigagem ordinária. As amostras foram analisadas através de detecção por fotoionização (PID). Mapas krigados obtidos a partir de amostragens com redução crescente do número de amostras foram analisados, sendo adotadas amostragens aleatórias e sequenciais. Foram construídos mapas com 100\%, 75\%, 50\% e $25 \%$ dos dados, em cada nível de profundidade. A otimização da malha foi julgada a partir de três parâmetros: 1) a variografia de cada mapa krigado; 2) a diferença RMS (Root Mean Square) entre cada mapa krigado com redução de dados em relação ao respectivo mapa krigado com $100 \%$ dos dados e; 3) a área impactada, considerando como tal pontos com concentrações de VOCs acima de $20 \mathrm{ppm}$. Com a redução do número de amostras, a diferença RMS tende a aumentar, enquanto que a área impactada pouco se altera, sendo este efeito sensivelmente maior para o nível de profundidade de $1,5 \mathrm{~m}$. Considerando que os parâmetros de variografia, a diferença RMS e a área impactada, não se alteram substancialmente com a redução no número de dados até o limite de $50 \%$, pode-se recomendar, por razões econômicas, a redução no número de amostras até esse limite.
\end{abstract}

Palavras-chave: contaminação, hidrocarboneto, geoestatística, diagnóstico geoambiental.

ABSTRACT This work aims a sampling mesh optimization to detect a possible contamination by volatile organic compounds (VOCs) in an area of storage of petroleum products, of around 20 hectares, where 2.361 soil samples were collected, 0.5 $\mathrm{m}, 1.0 \mathrm{~m}$ and $1.5 \mathrm{~m}$ deep, at each sampling point. The technique used was the ordinary kriging. The soil samples were analyzed by PID technique (Photon Ionization Detection). The strategy adopted was the analysis of krigged maps obtained from sampling with increasing reduction in the number of samples. Random and sequential sampling were adopted. Krigged maps were constructed with $100 \%, 75 \%, 50 \%$ and $25 \%$ of all available data, at each depth level. Mesh optimization was judged from three parameters: 1 ) the variography of each krigged map; 2) the RMS difference (Root Mean Square) between each krigged map with data reduction and its corresponding krigged map with $100 \%$ of data and; 3 ) the impacted area, according to each krigged map, considering each contaminated point as that with VOCs concentrations greater than $20 \mathrm{ppm}$. The number of samples reduction tends to increase the RMS difference while the impacted area almost do not alters, being this effect higher for the $1,5 \mathrm{~m}$ depth level. Considering that variography parameters, the RMS difference and the impacted area do not change substantially with the reduction in the number of samples, until the limit of $50 \%$, it can be recommended, for economic reasons, the reduction in the number of samples up to this limit.

Key-words: contamination, hydrocarbon, geostatistics, geoenvironmental diagnosis.

\section{INTRODUÇÃO}

Instalações para escoamento e armazenagem de petróleo, como terminais, oleodutos e parques de tanques estão constantemente sujeitas a eventos que podem resultar na contaminação do solo e da água subterrânea. Por mais bem projetadas que sejam essas instalações, e apesar da manutenção constante e respeito às boas práticas de segurança operacional, após décadas de operação é comum se observar a ocorrência de algum impacto ambiental na área. Atualmente diversas instalações desse tipo são avaliadas e monitoradas com o objetivo de se detectar impactos causados por eventos pretéritos. Ao conjunto de ações e análises efetuadas com o objetivo de identificar e quantificar o impacto sobre o solo e a água subterrânea dá-se o nome de diagnóstico geoambiental.

Para o diagnóstico geoambiental são normalmente realizadas sondagens ambientais com coleta de amostras de solo, levantamentos geofísicos como GPR e imageamento elétrico, coleta de dados hidrogeológicos (como nível freático, condutividade hidráulica, determinação de parâmetros hidrodinâmicos, instalação de poços de monitoramento e coleta de amostras de água), análises geoquímicas e geotécnicas de solo e ensaios hidroquímicos.

As análises geoquímicas incluem levantamentos PID (Photo Ionization Detection). Um detector do tipo PID é 
um detector de gases. Detectores de fotoionização típicos medem compostos orgânicos voláteis e outros gases em concentrações desde $1 \mathrm{ppb}$ até $10.000 \mathrm{ppm}$. O detector de fotoionização (PID) é o tipo de detector mais eficiente e de baixo custo para a detecção de gases. Ele é capaz de fornecer leitura instantânea ou realizar um monitoramento contínuo. Esse equipamento é muito usado para fins militares, industriais, ou para fins de segurança do trabalho em ambientes confinados (CLEAN ENVIRONMENT BRASIL, 1995).

A motivação para a realização deste trabalho é a constatação de que muitos trabalhos de diagnostico geoambiental, baseados na análise dos resultados de ensaios com PID, para identificação de possíveis zonas impactadas por atividades de escoamento e armazenagem de petróleo e seus derivados, não possuem um estudo sobre a taxa ideal de amostragem de solo para quantificação dos elementos voláteis presentes. Isto pode resultar em levantamentos com número de amostras excessivamente baixo, prejudicando a qualidade do diagnóstico, ou excessivamente elevado, aumentando desnecessariamente os custos.

Este trabalho faz uso intensivo da principal técnica geoestatística de mapeamento: a krigagem. Esta técnica se constitui numa forma sofisticada de interpolação de dados, onde a função de interpolação é dada pelo variograma, que por sua vez é a representação local da continuidade espacial do fenômeno estudado. A krigagem é considerada uma técnica BLUE (Best Linear Unbiased Estimator), ou seja, é o melhor estimador linear não-tendencioso possível de se obter com os dados disponíveis. Além de fornecer um mapa com a maior representatividade possível, a krigagem fornece também um mapa associado de variância de estimativa local, o qual representa a incerteza na estimativa de cada ponto do mapa principal (ANDRIOTTI, 2003; GUERRA, 1988; JOURNEL, 1988; KITANIDIS, 1997; YAMAMOTO, 1996).

\section{DADOS UTILIZADOS}

Os dados utilizados neste trabalho são provenientes de uma investigação ambiental de uma área de armazenamento de petróleo, visando caracterizar a existência de compostos contaminantes derivados de hidrocarbonetos, pois havia na área relatos de diversas ocorrências de acidentes ambientais.

A área em estudo é constituída de sete tanques de armazenamento de petróleo em uma área de aproximadamente 20 hectares. No entanto, para fins de estimação por krigagem foi considerada uma área retangular com cerca de 36 hectares, a qual contém a área de tanques.

Foram feitas medições de VOCs em 787 pontos, a cada meio metro, ou seja, a $0,5 \mathrm{~m}, 1,0 \mathrm{~m}$ e $1,5 \mathrm{~m}$ de profundidade, totalizando 2361 medições, apresentadas na Figura 1.

Os ensaios PID foram realizados com o intuito de avaliar a presença de compostos orgânicos voláteis (VOCs) através de medição direta em subsuperfície, utilizando um detector portátil de gases, que detecta vapores de hidrocarbonetos, com possibilidade de exclusão do metano $-\mathrm{CH}_{4}$. Esta característica é importante porque o metano pode ocorrer naturalmente, e se essa exclusão não for feita, pode mascarar a ocorrência dos VOCs. $\mathrm{Na}$ análise dos dados considera-se que valores acima de 20 ppm são possivelmente indicativos da presença de contaminação por hidrocarbonetos no substrato da área em questão. Este valor de corte foi definido com base na tabela da CETESB apresentada em Boscov (2008), assim como no relatório de investigação da área, realizado por uma empresa contratada para este fim.

\section{METODOLOGIA}

Krigagem é um processo de estimativa de valores de variáveis distribuídas no espaço e no tempo, a partir de valores adjacentes enquanto considerados como interdependentes pelo semivariograma (LANDIM, 2003).

A Krigagem usa informações a partir do semivariograma para encontrar os pesos ótimos a serem associados às amostras que irão estimar um ponto. Como o semivariograma é uma função da distância entre locais de amostragens, mantendo-se o mesmo número de amostras, os pesos serão diferentes de acordo com o seu arranjo geográfico.

Com a krigagem, torna-se viável a melhor estimativa possível para locais não amostrados, pela minimização da variância do erro. Todavia, não há garantia que o mapa obtido pela krigagem tenha o mesmo semivariograma e a mesma variância que os dados originais, pois se trata, pela própria natureza do método, de um mapa com valores suavizados. Esta questão é resolvida pela simulação, que permite infinitas realizações de mapas, cada qual com dados originais.

A krigagem ordinária é um interpolador exato no sentido que os valores interpolados coincidem com os valores dos pontos amostrais. A variância da krigagem ordinária fornece informação importante sobre a confiabilidade dos valores interpolados (BURROUGH, 1998). A técnica de krigagem ordinária supõe que os dados apresentam distribuição normal de frequências.

Neste trabalho foram gerados mapas da distribuição de VOCs, através da krigagem ordinária, nos três níveis de profundidades em que as amostras foram coletadas. Para cada nível de profundidade foi gerado um mapa utilizando $100 \%$ dos dados e mapas alternativos com $75 \%, 50 \%$ e $25 \%$ dos dados amostrados, segundo dois critérios alternativos: aleatório e sequencial. Para a geração de cada mapa foi adotado o seguinte método: $\begin{array}{ccccr}\text { Adoção } & \text { dos dados } & \text { do } & \text { levantamen- } \\ \text { to } & \text { PID } & \text { adquiridos na } & \text { área } & \text { estudada. } \\ & \text { Utilização } & \text { do programa } & \text { Enterprise } & \text { Guide }^{\circledR}\end{array}$ (DAVIS, 2007) para amostrar aleatoriamente os dados segundo as percentagens desejadas.

Geração dos arquivos de dados sequenciais segundo as percentagens desejadas, através da manipulação dos arquivos de dados no programa Excel ${ }^{\circledR}$. Para a amostragem sequencial com $75 \%$ dos dados efetuou-se a exclusão de 1 
amostra a cada 4 do arquivo original (100\% dos dados). Para a amostragem sequencial com $50 \%$ dos dados retirou-se uma amostra a cada três do arquivo com $75 \%$ dos dados. Já para a amostragem sequencial com $25 \%$ dos dados se excluiu uma amostra a cada duas do arquivo com $50 \%$ dos dados.

Análise exploratória dos dados utilizando o Programa GSLIB (LANDIM \& MONTEIRO, 2000).

Ajuste dos variogramas utilizando o Programa GS+ for Windows (GAMMA DESIGN, 2002).

Krigagem dos dados utilizando o programa GSLIB.

Geração dos mapas de krigagem e de variância de estimativa pelo GSLIB. Por fim, foi realizado o cálculo da diferença RMS (diferença média quadrática) para todas as percentagens de amostragens aleatórias e sequenciais em relação ao respectivo mapa krigado com $100 \%$ dos dados, através do programa Excel ${ }^{\circledR}$.

O fluxograma da Figura 2 resume, de forma esquemática, a metodologia adotada neste trabalho. Embora a Figura 2 indique a análise completa apenas para o nível de profundidade de 1,0 m, o processo completo também foi efetuado para os outros dois níveis de profundidade indicados na figura. Trata-se apenas de uma simplificação gráfica do fluxograma.

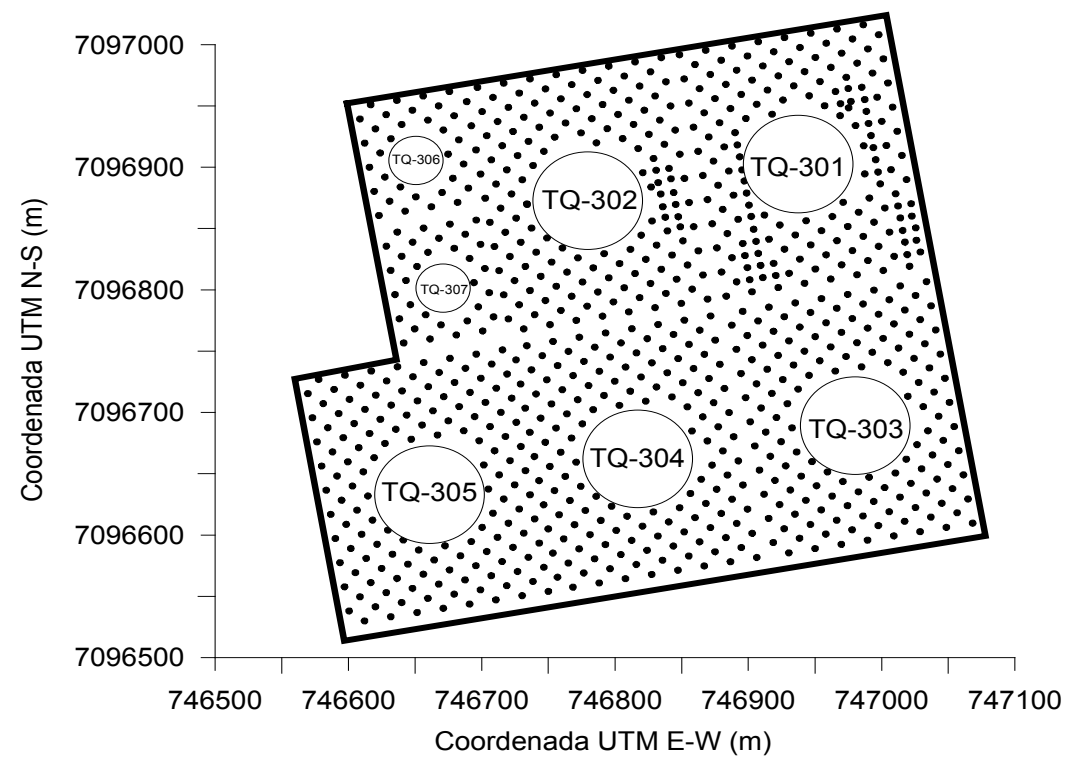

Figura 1 - Mapa da área de estudo com localização de tanques e pontos de medições de VOCs.

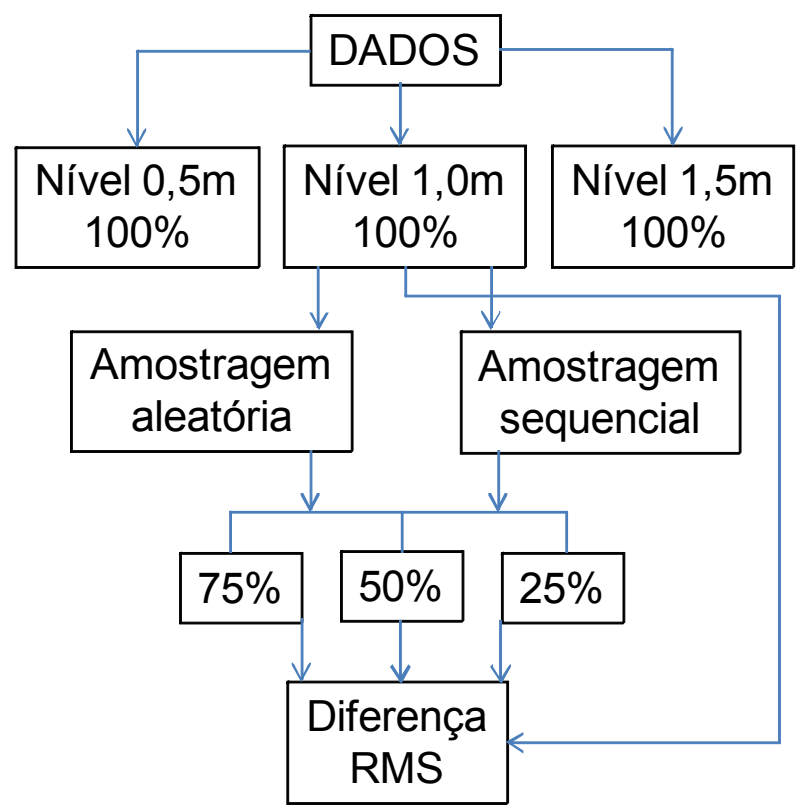

Figura 2 - Fluxograma com a rotina de trabalho adotada neste trabalho. 
A análise dos dados se deu de acordo com o seguinte procedimento: após a definição dos arquivos de dados, por nível e por método de amostragem, foi gerado o corresponde mapa de localização das amostras (módulo LOCMAP do GSLIB), os dados foram normalizados (módulo NSCORE do GSLIB), realizada a análise variográfica (geração do variograma experimental e ajuste pelos modelos teóricos) no programa GS+, krigagem ordinária da variável normalizada (módulo KT3D do GSLIB), transformação inversa dos valores krigados da variável normalizada em ppm de VOCs (módulo BACKTR do GSLIB) e, por fim, geração dos mapas de VOCs krigados (módulo PIXELPLT do GSLIB).

Para quantificar a semelhança entre os mapas krigados com um certo percentual $\mathrm{x}$ de amostras em relação aos mapas obtidos com $100 \%$ dos dados, foi adotada a diferença RMS (Root Mean Square). A diferença RMS indica o quanto um mapa difere, em média, do outro. Ela é definida, em ppm, pela equação (1).

\section{(1)}

A fim de estimar o percentual de área impactada nos mapas obtidos neste trabalho, considerou-se que, 1) de acordo com a tabela da CETESB (BOSCOV, 2008), as concentrações mínimas de VOCs que exigem intervenção em ambiente industrial variam de $0,15 \mathrm{ppm}$ a $95 \mathrm{ppm}$, de acordo com a substância considerada; e 2) o valor de corte adotado no relatório de investigação da área foi de 20 ppm para VOCs em solo; este foi o valor de corte adotado neste trabalho para definir se uma área está ou não impactada pela presença de compostos orgânicos voláteis no solo.

\section{RESULTADOS}

Neste item são apresentados os resultados alcançados para as krigagens efetuadas. São analisados os resultados para cada nível de profundidade de forma independente. Para cada nível amostrado de profundidade, os dados foram krigados com redução crescente no percentual de amostras, obtidos por amostragens aleatória e sequencial, a fim de avaliar o efeito da redução do números de amostras sobre a distribuição espacial dos contaminantes.

\section{Nível de profundidade 0,5 metro}

A Figura 3a apresenta, do lado esquerdo, o mapa de localização com os valores de VOC de todas as 787 amostras do nível 0,5 m. Do lado direito se encontra o correspondente mapa krigado, obtido pela aplicação da metodologia adotada neste trabalho (vide Figura 2). Os mapas krigados neste trabalho são compostos por 360 mil pixels, cada um com área de $1 \mathrm{~m}$ x $1 \mathrm{~m}$. O mapa krigado apresenta um padrão de distribuição de valores que respeita os valores amostrados. A quantificação do volume de contaminantes a extrair da área fica facilitada em relação ao que se dispunha antes da análise geoestatística. Na Figura 3a pode-se observar uma maior concentração de VOCs na porção sulsudoeste, próximo aos tanques TQ-303, TQ-304 e TQ-305.

\section{Amostragem aleatória}

A Figura 4 apresenta, do lado esquerdo, os mapas de localização das amostras, escolhidas aleatoriamente, para o nível $0,5 \mathrm{~m}$. À direita são apresentados os mapas krigados de VOCs correspondentes. Esta figura contém os mapas correspondentes a 75\% (parte superior), 50\% (parte intermediária) e $25 \%$ dos dados (parte inferior), respectivamente. As diferenças RMS entre os mapas krigados desta figura e o mapa com 100\% dos dados (Figura 3a) foram de 0,51 ppm, 0,68 ppm e 0,59 ppm, respectivamente. Observa-se que, de modo semelhante à Figura 3a, as maiores concentrações de VOCs se encontram na parte sul-sudoeste. Vê-se ainda que com a redução no número de amostras, reduz-se a área impactada e há uma tendência de manter a contaminação apenas próximo ao TQ-305.

Com o objetivo de avaliar o efeito da amostragem aleatória sobre os resultados alcançados nesta etapa do trabalho, foram realizadas mais três amostragens aleatórias independentes para as amostras do nível de profundidade $0,5 \mathrm{~m}$.

\section{Amostragem sequencial}

A Figura 5 apresenta, à esquerda, os mapas de localização das amostras, escolhidas sequencialmente, para o nível $0,5 \mathrm{~m}$. À direita são apresentados os mapas krigados de VOCs correspondentes. Esta figura contém os mapas correspondentes a 75\% (parte superior), 50\% (parte intermediária) e $25 \%$ dos dados (parte inferior), respectivamente. Os valores de diferença RMS entre os mapas krigados da Figura 5 e o mapa krigado da Figura 3a foram de $0,33 \mathrm{ppm}, 0,56 \mathrm{ppm}$ e $0,59 \mathrm{ppm}$, respectivamente, portanto, da mesma ordem de grandeza daqueles calculados para as amostragens aleatórias do nível 0,5 m. Nos mapas krigados para $75 \%$ e $50 \%$ dos dados, as maiores concentrações de VOCs se localizam na parte sul-sudoeste do mapa. No mapa krigado para $25 \%$ dos dados a ausência da contaminação próxima ao TQ-305 é compensada pela presença de um ponto de contaminação na parte centro-leste do mapa, resultando em pequeno valor na diferença RMS calculada.

\section{Nível de profundidade 1,0 metro}

A Figura 3b apresenta, do lado esquerdo, o mapa de localização das 787 amostras do nível 1,0 metro com seus valores (ppm de VOCs). Do lado direito está o correspondente mapa de VOCs krigado. Observa-se que no mapa krigado há uma indicação de maior concentração de VOCs no entorno dos tanques localizados na porção sul da área e a leste do TQ-301. Além disso percebe-se um aumento da área impactada em relação ao nível $0,5 \mathrm{~m}$.

\section{Amostragem aleatória}

A Figura 6 apresenta os mapas de localização das 

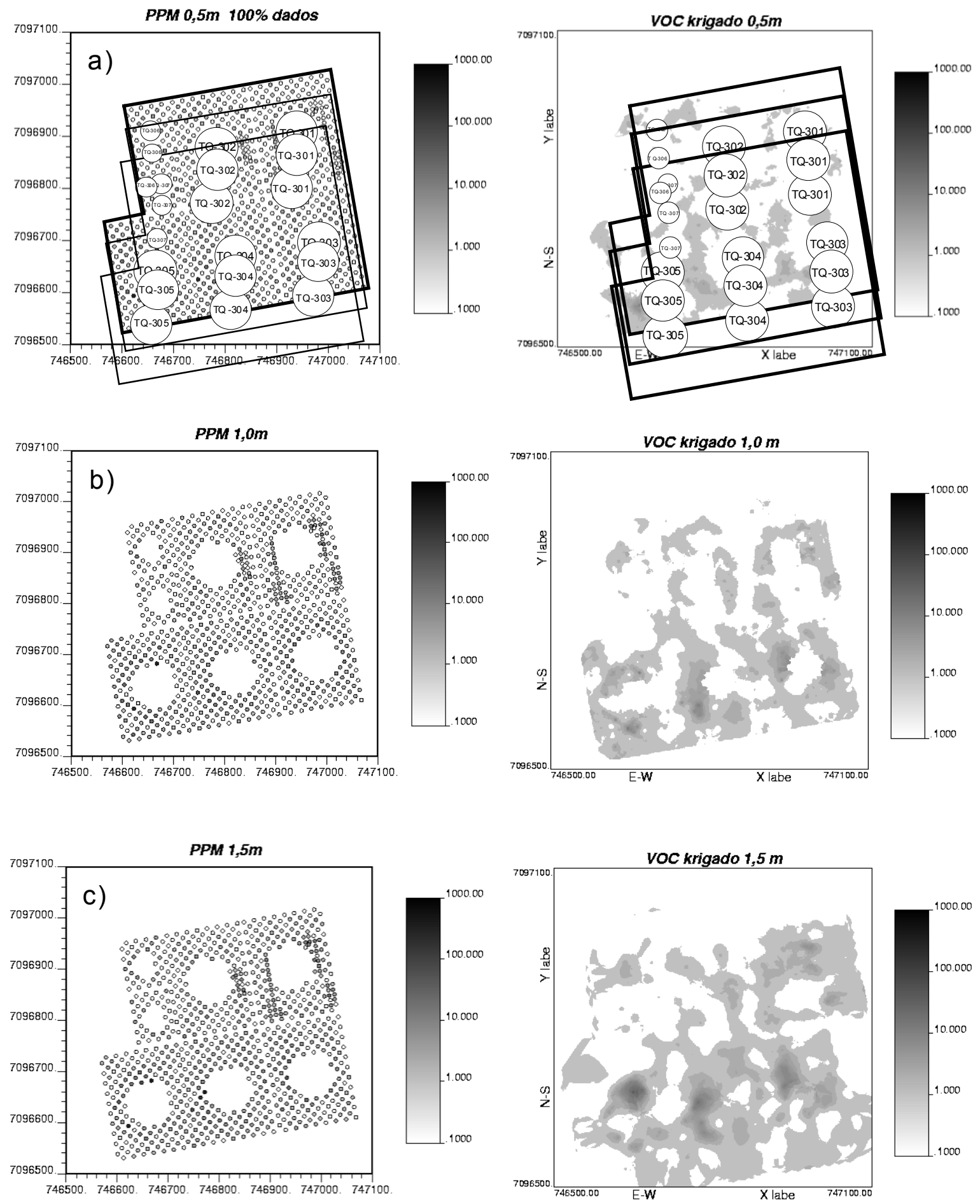

Figura 3 - Mapa de localização e valores medidos de VOCs (esquerda) e correspondente mapa krigado (direita) para: a) amostras do nível 0,5 m; b) amostras do nível 1,0 m; e c) amostras do nível 1,5 m. 

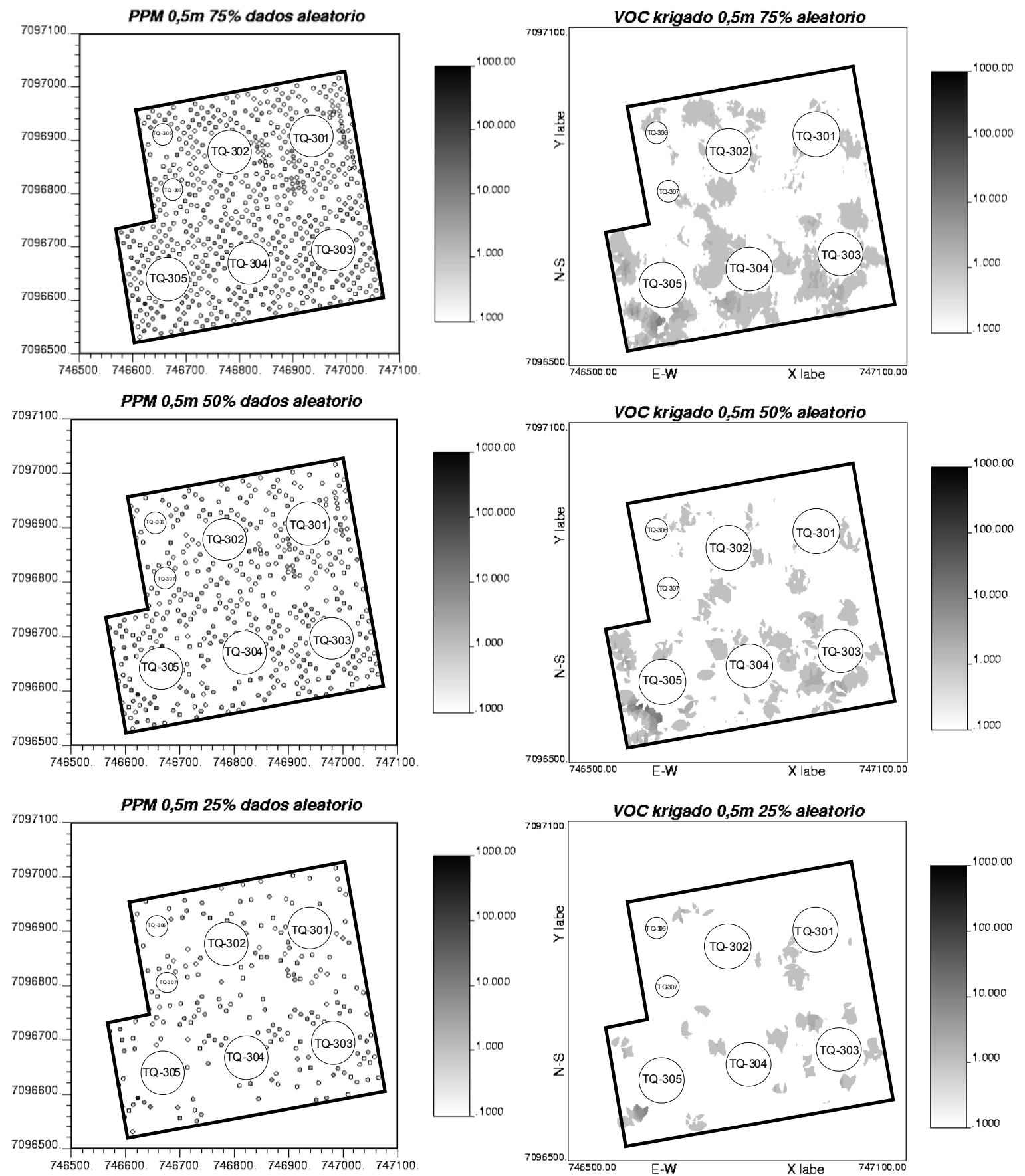

Figura 4 - Resultados para amostragem aleatória no nível $0,5 \mathrm{~m}$. Na parte superior são apresentados os gráficos relativos à amostragem com $75 \%$ dos dados, na parte intermediária com $50 \%$, e na parte inferior, com $25 \%$ dos dados. Do lado esquerdo se encontram os mapas de localização com os valores de VOC amostrados e, do lado direito, os correspondentes mapas krigados. 

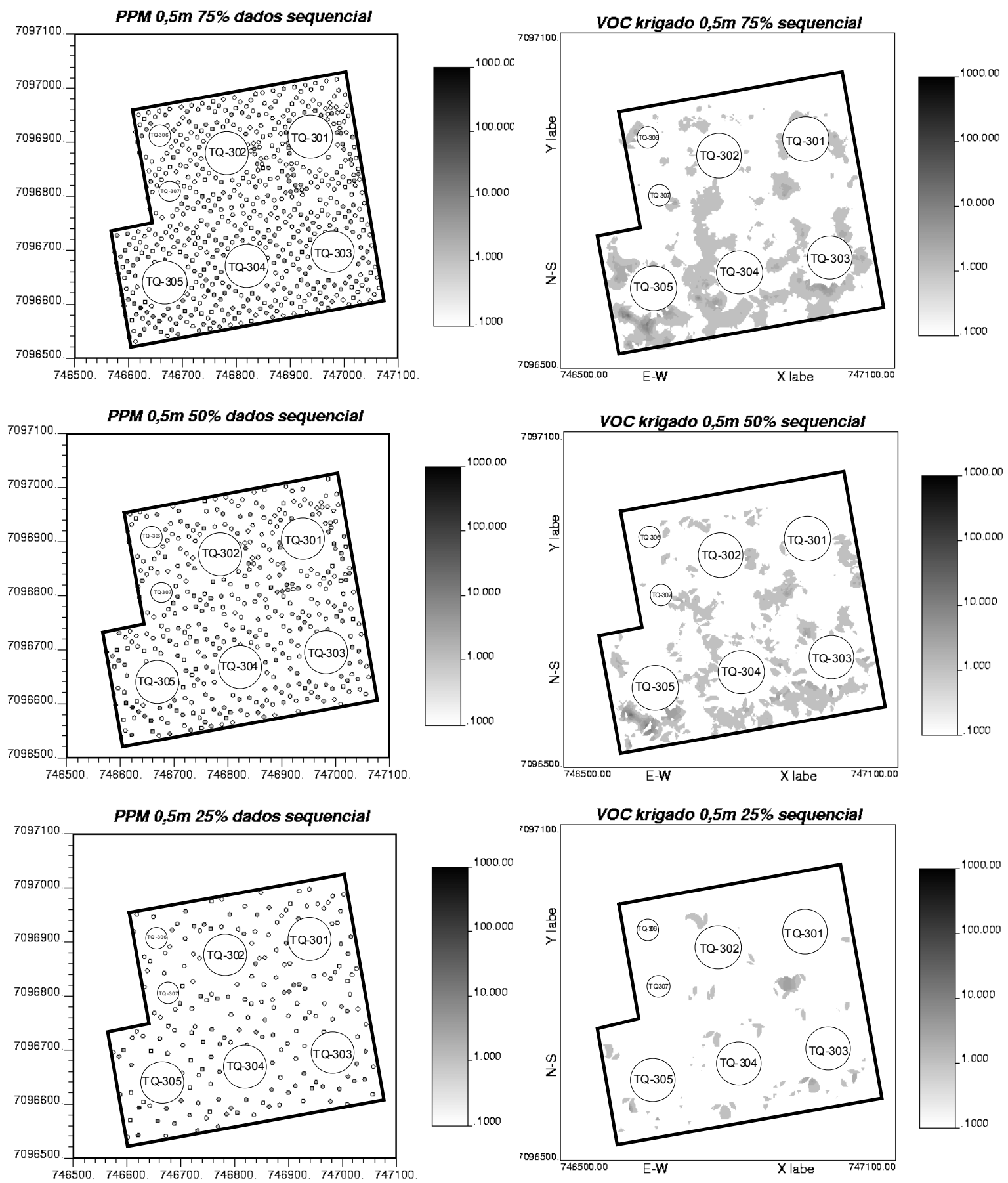

Figura 5 - Resultados para amostragem sequencial no nível $0,5 \mathrm{~m}$. Na parte superior são apresentados os gráficos relativos à amostragem com $75 \%$ dos dados, na parte intermediária com $50 \%$, e na parte inferior, com $25 \%$ dos dados. Do lado esquerdo se encontram os mapas de localização com os valores de VOC amostrados e, do lado direito, os correspondentes mapas krigados. 

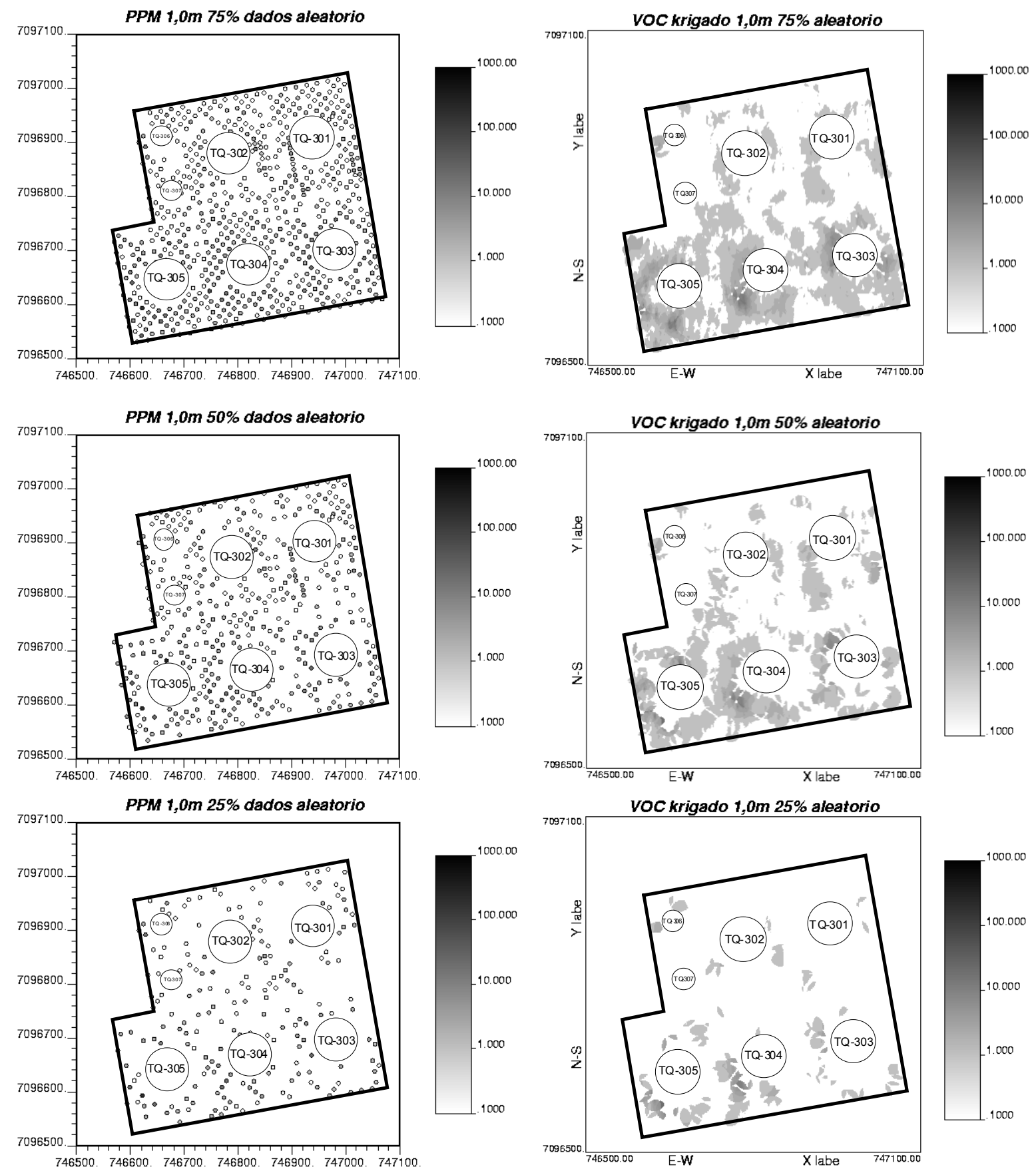

Figura 6 - Resultados para amostragem aleatória no nível 1,0 m. Na parte superior são apresentados os gráficos relativos à amostragem com $75 \%$ dos dados, na parte intermediária com $50 \%$, e na parte inferior, com $25 \%$ dos dados. Do lado esquerdo se e contram os mapas de localização com os valores de VOC amostrados e, do lado direito, os correspondentes mapas krigados. 
amostras, escolhidas aleatoriamente, e os correspondentes mapas krigados, para o nível 1,0 m. As diferenças RMS entre os mapas krigados desta figura e o mapa com $100 \%$ dos dados (Figura 3b) foram de $0,57 \mathrm{ppm}, 0,70 \mathrm{ppm}$ e 0,74 ppm, para, respectivamente, $75 \%, 50 \%$ e $25 \%$ dos dados.

Em relação ao mapa krigado da Figura 3b, observa-se que há uma redução da área impactada com a redução no número de amostras, como também a contaminação tende a se manter apenas na porção sul-sudoeste do mapa.

\section{Amostragem sequencial}

A Figura 7 apresenta os mapas de localização das amostras, escolhidas sequencialmente, e os correspondentes mapas krigados, para o nível 1,0 m. Os valores de diferença RMS entre os mapas krigados desta figura e o mapa krigado da Figura $3 \mathrm{~b}$ foram de 0,63 ppm, 0,70 ppm e 0,84 ppm, para $75 \%, 50 \%$ e $25 \%$ dos dados, respectivamente. Estes valores também são da mesma ordem de grandeza daqueles obtidos para os mapas com amostragem aleatória. Os mapas krigados da Figura 7 apresentam o comportamento semelhante àqueles da Figura 6, exceto que mantêm a contaminação a leste do TQ-301.

\section{Nível de profundidade 1,5 metro}

A Figura 3c apresenta, do lado esquerdo, o mapa de localização das 787 amostras do nível 1,5 metro com os respectivos valores medidos de concentração de VOCs. Do lado direito está o correspondente mapa de VOCs krigado. Observa-se que no mapa da direita há a indicação de uma maior concentração de VOCs no entorno dos tanques localizados na porção sul e do TQ-301, bem como um aumento substancial da área impactada em relação aos níveis mais superficiais.

\section{Amostragem aleatória}

A Figura 8 apresenta os mapas de localização das amostras, escolhidas aleatoriamente, e os correspondentes mapas krigados, para o nível 1,5 m. As diferenças RMS entre os mapas krigados da Figura 8 e o mapa krigado da Figura 3c foram de 1,50 ppm, 1,91 ppm e 1,36 ppm, para $75 \%, 50 \%$ e $25 \%$ dos dados, respectivamente. Nesta figura, a distribuição espacial dos contaminantes é parecida com aquela da Figura 7, no sentido que ocorre uma redução da área contaminada com a diminuição do número de amostras e que a contaminação se concentra na parte sul-sudoeste do mapa e a leste do TQ-301.

\section{Amostragem sequencial}

A Figura 9 apresenta os mapas de localização das amostras, escolhidas sequencialmente, e os correspondentes mapas krigados, para o nível 1,5 m. As diferenças RMS entre os mapas krigados desta figura e o mapa krigado da Figura $3 \mathrm{c}$ foram de 2,33 ppm, 1,37 ppm e 1,41 ppm, para 75\%, 50\% e $25 \%$ dos dados, respectivamente. As diferenças RMS para o nível 1,5 m apresentaram uma ordem de grandeza superior àquelas calculadas para os níveis mais superficiais do terreno.

Os mapas krigados da Figura 9 apresentam um comportamento semelhante ao dos mapas krigados da Figura 8, embora a área impactada de alguns mapas seja maior ou mais fragmentada.

Efeito da hidrogeologia na dispersão dos contaminantes

$\mathrm{O}$ relatório de investigação da área diz que:

O sentido de fluxo das águas subterrâneas dentro da área se dá de sudoeste para nordeste, fazendo com que as águas subterrâneas não se dirijam para o canal de drenagem localizado nas bordas oeste e sul da área.

A contaminação com hidrocarbonetos voláteis foi tanto maiorquantomaispróximodasbordasdosdiquesdecontenção.

Uma vez que o sentido preferencial do fluxo subterrâneo se dá para NE, a área de tanques encontra-se sujeita a eventuais contaminações provenientes dos setores oeste, sudoeste e sul.

Os mapas krigados deste trabalho indicam, de modo geral, uma maior concentração de VOC's a sul/sudoeste dos tanques TQ-303, TQ-304 e TQ-305, e a leste/nordeste do tanque TQ-301. Este padrão pode ser especialmente visualizado no lado direito das Figuras 3a, 3b e 3c. Isto indica que não há uma clara evidência de que o sentido de fluxo da água subterrânea, conforme descrito no relatório de investigação da área, seja a principal variável de controle na dispersão dos contaminantes na área. Também não se confirma, de acordo com os mapas krigados neste trabalho, a maior concentração de contaminantes próximo dos diques de contenção que existem entre os tanques. Conseqüentemente, a terceira hipótese levantada, de que a área estaria especialmente vulnerável a contaminações provindas de setores a oeste, sudoeste e sul da área de tanques também não é confirmada pelos mapas obtidos neste trabalho.

\section{Análise dos variogramas}

Alcance médio

A fim de analisar a robustez dos semivariogramas utilizados neste trabalho, especialmente para o caso da amostragem aleatória, foram construídos vários semivariogramas, sendo que para o nível $0,5 \mathrm{~m}$ foram quatro, um para cada amostragem aleatória. A Figura 10 apresenta o alcance médio para todos os conjuntos de dados utilizados neste trabalho. Observar que, além das percentagens normalmente utilizadas para amostragem (100\%, 75\%, 50\% e 25\%), foram realizadas também amostragens aleatórias com 90\%, 80\%, $70 \%, 60 \%, 40 \%$ e $30 \%$. Isto foi feito com o objetivo de dar consistência à análise variográfica. Nesta figura observa-se que o alcance médio é aproximadamente constante para todas as amostragens com um número de amostras entre $100 \%$ e 50\%. Para um número de amostras inferior a $50 \%$ podem ocorrer alterações consideráveis no valor desse parâmetro, com uma tendência de rápido crescimento com a redução do número de amostras. 

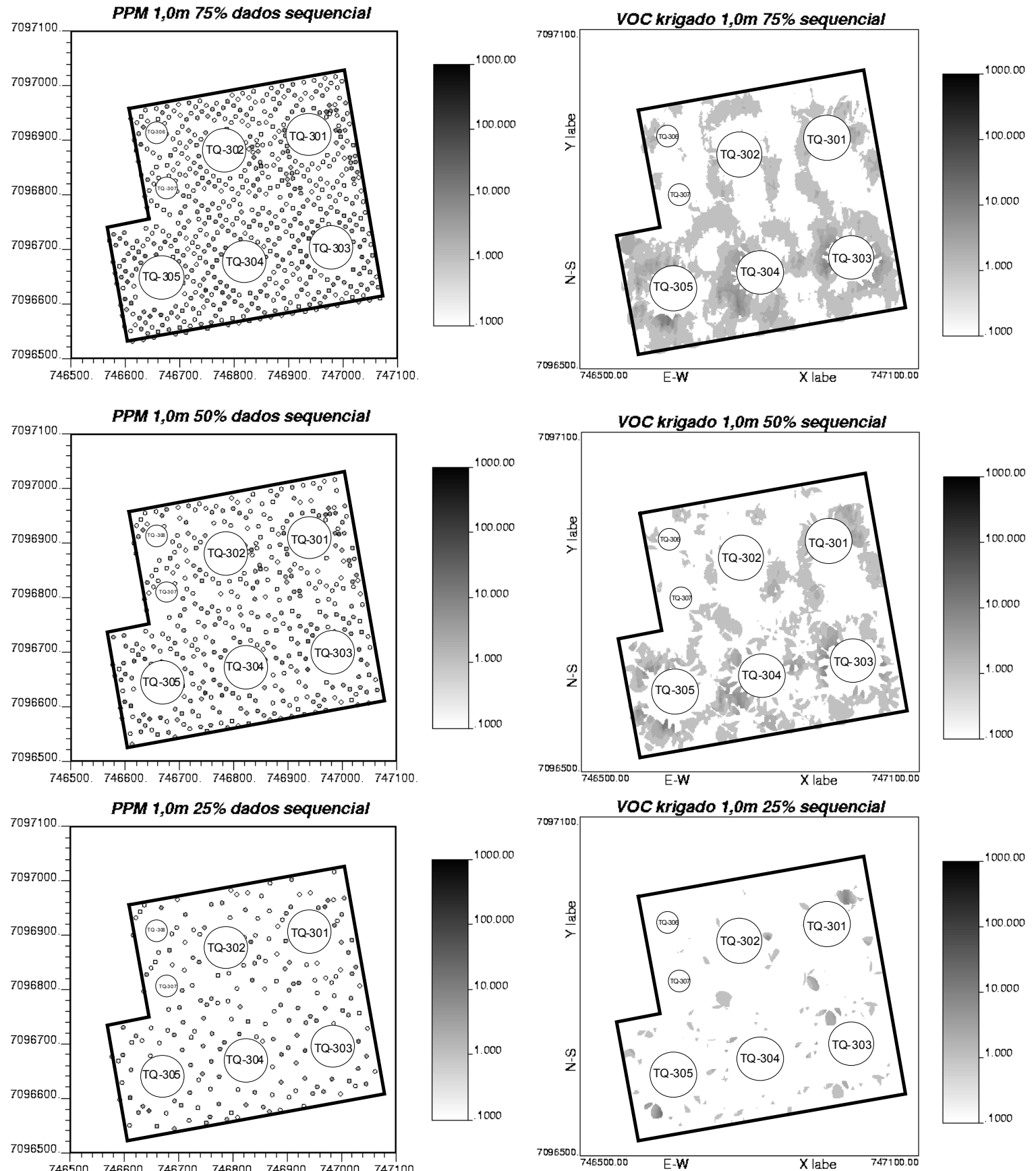

Figura 7 - Resultados para amostragem sequencial no nível 1,0 m. Na parte superior são apresentados os gráficos relativos à amostragem com $75 \%$ dos dados, na parte intermediária com $50 \%$, e na parte inferior, com $25 \%$ dos dados. Do lado esquerdo se encontram os mapas de localização com os valores de VOC amostrados e, do lado direito, os correspondentes mapas krigados. 

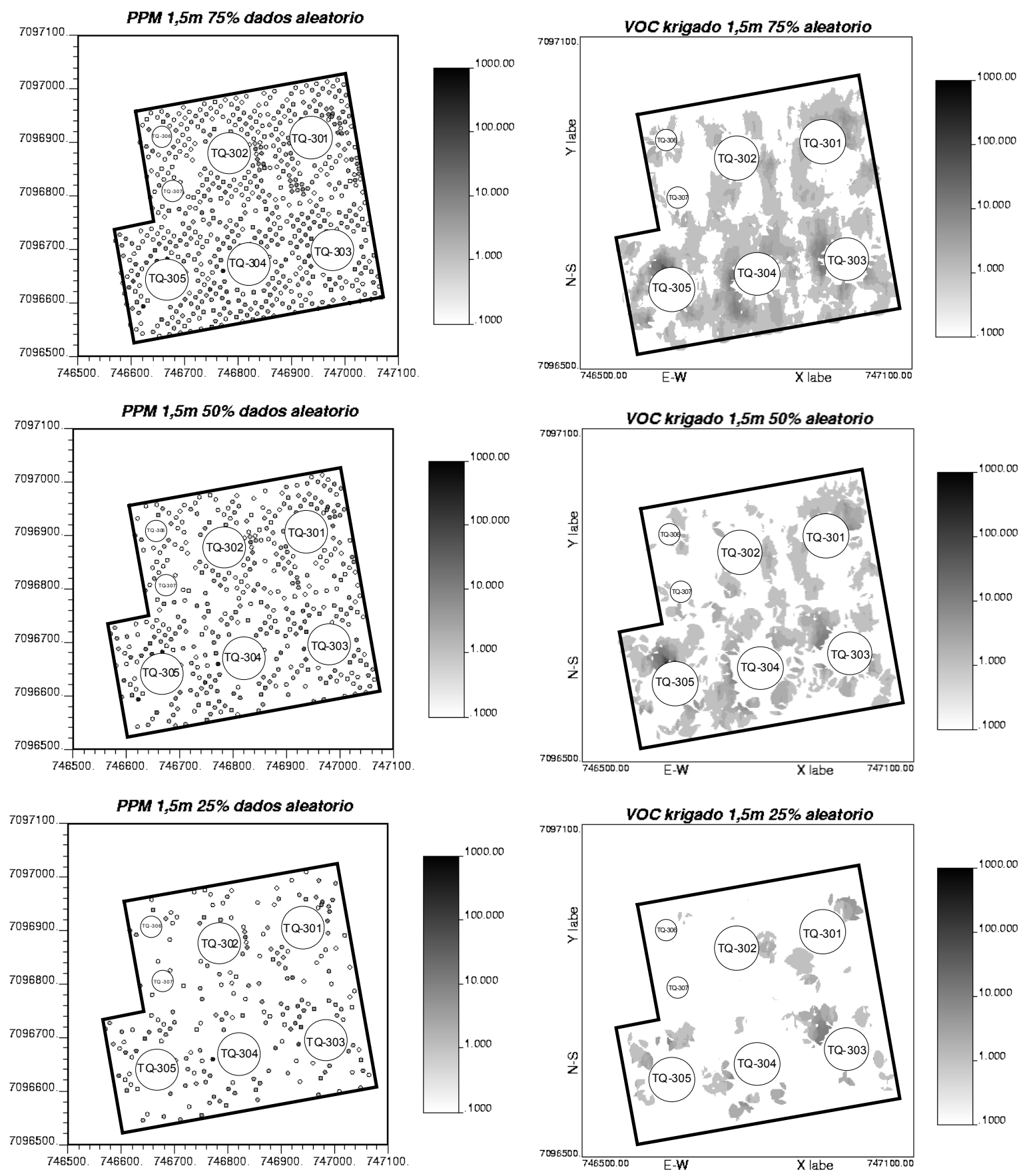

Figura 8 - Resultados para amostragem aleatória no nível 1,5 m. Na parte superior são apresentados os gráficos relativos à amostragem com $75 \%$ dos dados, na parte intermediária com $50 \%$, e na parte inferior, com $25 \%$ dos dados. Do lado esquerdo se encontram os mapas de localização com os valores de VOC amostrados e, do lado direito, os correspondentes mapas krigados. 

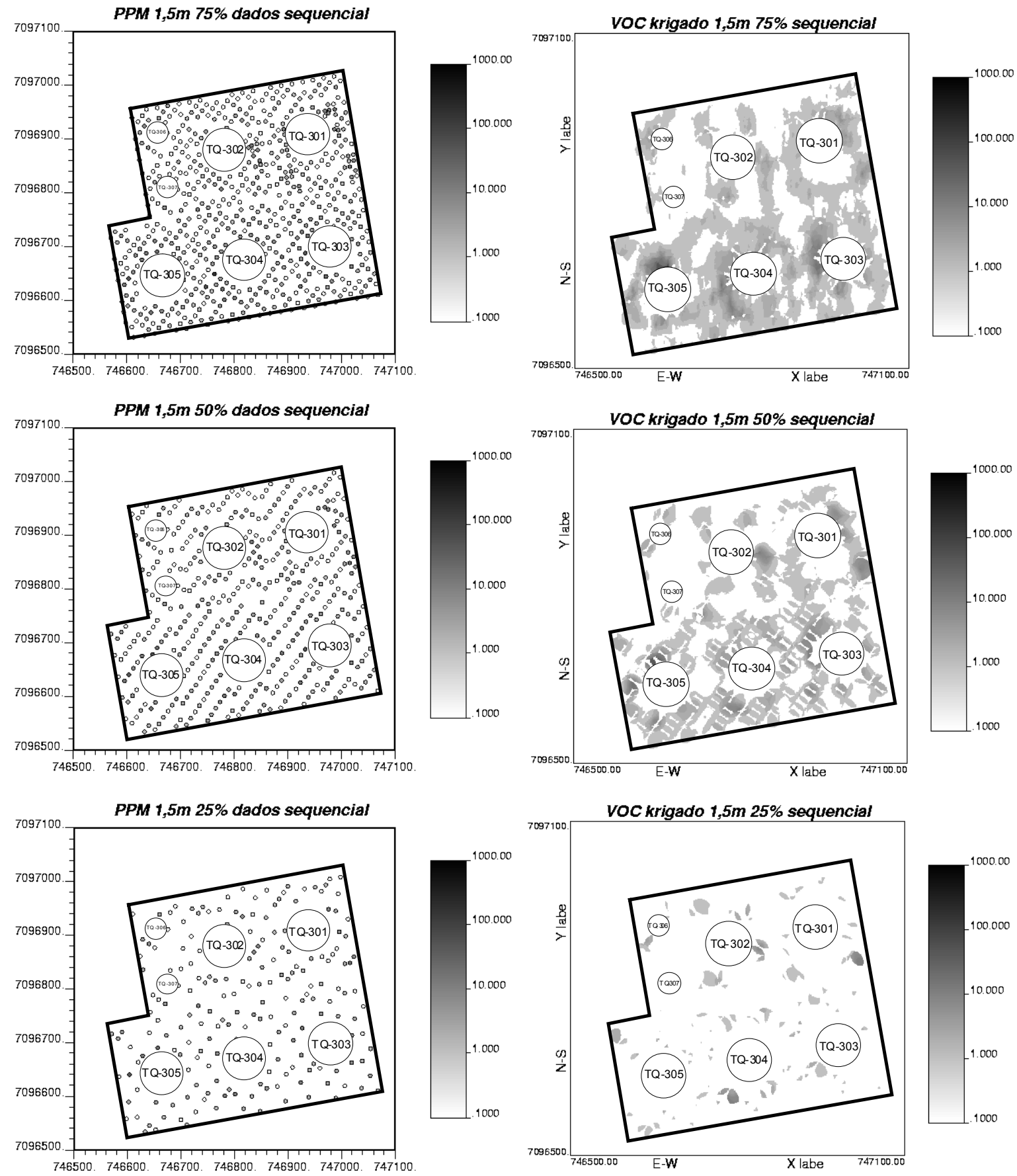

Figura 9 - Resultados para amostragem sequencial no nível 1,5 m. Na parte superior são apresentados os gráficos relativos à amostragem com $75 \%$ dos dados, na parte intermediária com $50 \%$, e na parte inferior, com $25 \%$ dos dados. Do lado esquerdo se encontram os mapas de localização com os valores de VOC amostrados e, do lado direito, os correspondentes mapas krigados. 


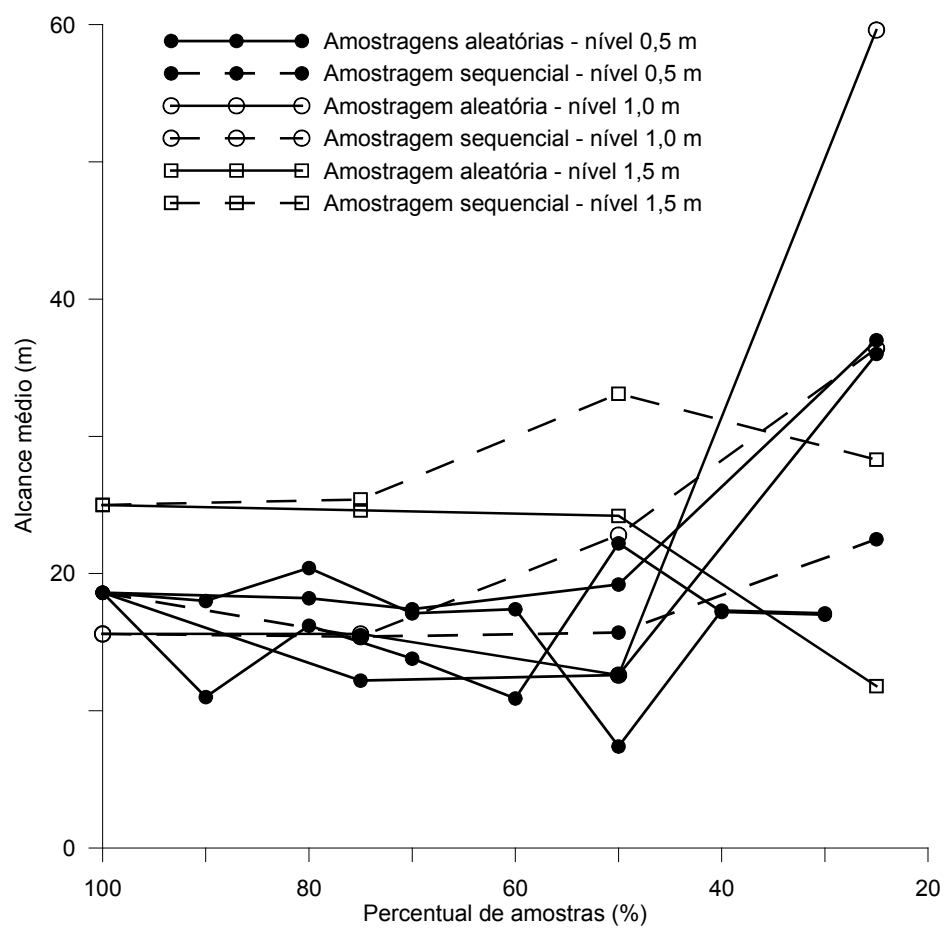

Figura 10 - Alcance médio dos semivariogramas utilizados para geração dos mapas 2D de concentração de VOCs.

\section{Efeito pepita}

A Figura 11 apresenta os valores do efeito pepita para todos os conjuntos de dados utilizados neste trabalho. Como na Figura 10, além das percentagens normalmente utilizadas, foram realizadas mais amostragens aleatórias. Nesta figura observa-se que o efeito pepita apresenta um suave decréscimo linear com a redução do número de amostras (exceto no caso do nível $1,0 \mathrm{~m}$ com $25 \%$ das amostras). Isto representa uma pequena redução do nível de aleatoriedade com a redução do número de amostras analisadas. Em geral, um número maior de amostras está associado a uma maior variabilidade nos valores medidos, bem como a maior presença de ruídos de amostragem e/ou de medição.

\section{Variância de dispersão}

A Figura 12 apresenta os valores de variância de dispersão para todos os conjuntos de dados utilizados neste trabalho. Observa-se nesta figura que a variância de dispersão apresenta um comportamento aproximadamente constante para qualquer número de amostras e para os dois tipos de amostragem. No caso do nível de profundidade 1,0 m o seu comportamento é semelhante ao do efeito pepita (vide Figura 11). Considerando que a variância de dispersão corresponde à soma entre o efeito pepita e a variância estrutural, esse comportamento da variância de dispersão é derivado do próprio comportamento do efeito pepita.

\section{Diferença RMS}

Com o objetivo de quantificar a diferença entre os mapas krigados com redução de amostras em relação aos mapas obtidos com $100 \%$ dos dados, foi adotada a diferença RMS, conforme definida na equação (1). Como exemplo, a Figura 13 apresenta os valores de diferença RMS para quatro amostragens aleatórias e uma sequencial, no nível de profundidade $0,5 \mathrm{~m}$. Observa-se nesta figura que a diferença RMS nesse nível de profundidade apresenta uma taxa de crescimento aproximadamente constante e linear com a redução do número de amostras, para os dois tipos de amostragem.

\section{Percentual de área impactada nos mapas krigados}

Com o objetivo de avaliar a variação na área impactada (concentrações de VOCs acima de 20 ppm) como resultado do processo com redução do número de dados, foram obtidos os valores apresentados na Figura 14, para os três níveis de profundidade investigados. Devese ressaltar que o percentual de área impactada considera toda a área krigada, excedendo a área de tanques.

O efeito da redução do número de amostras em relação à área impactada foi muito pequeno para os níveis de profundidade de $0,5 \mathrm{~m}$ e $1,0 \mathrm{~m}$. No entanto se observa um aumento expressivo da área impactada, para o nível de profundidade 1,5 $\mathrm{m}$, como resultado da redução do número de amostras, para ambas as amostragens (aleatória e sequencial). Esse fenômeno também pode ser observado diretamente nos mapas krigados, exceto para aqueles com $25 \%$ dos dados originais. 


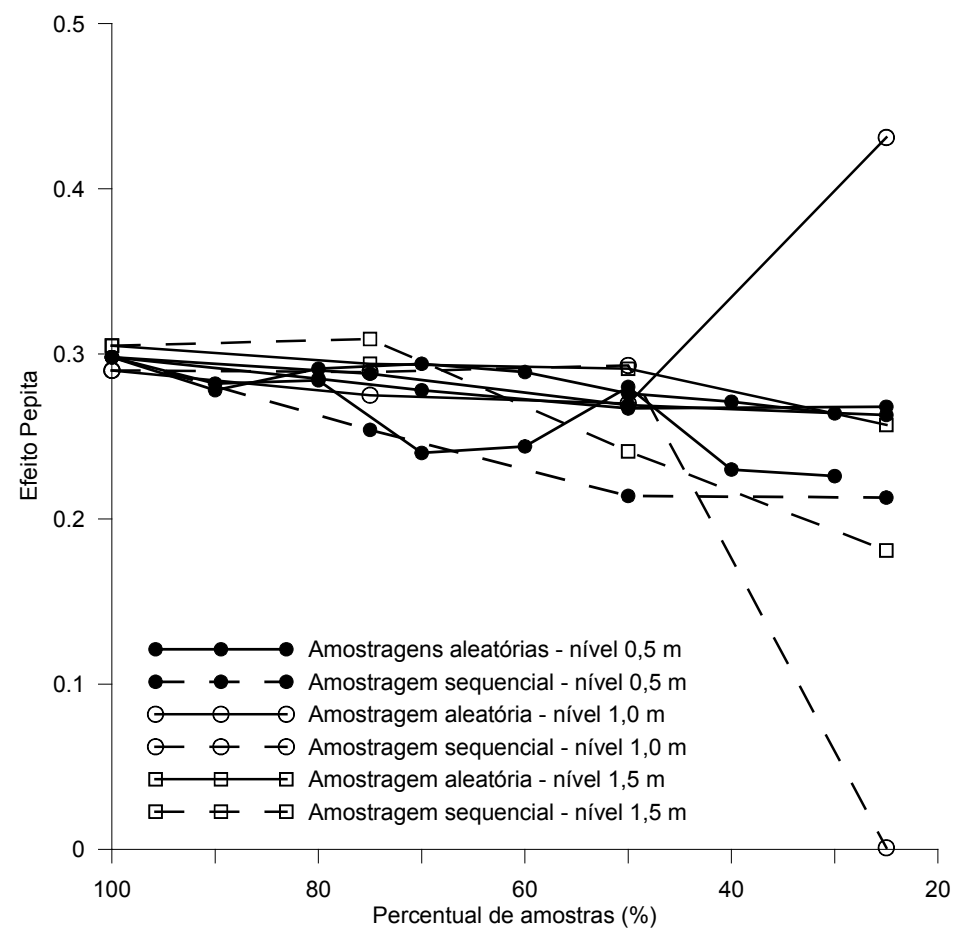

Figura 11 - Efeito pepita dos semiveriogramas utilizados para geração dos mapas 2D de concentração de VOCs.

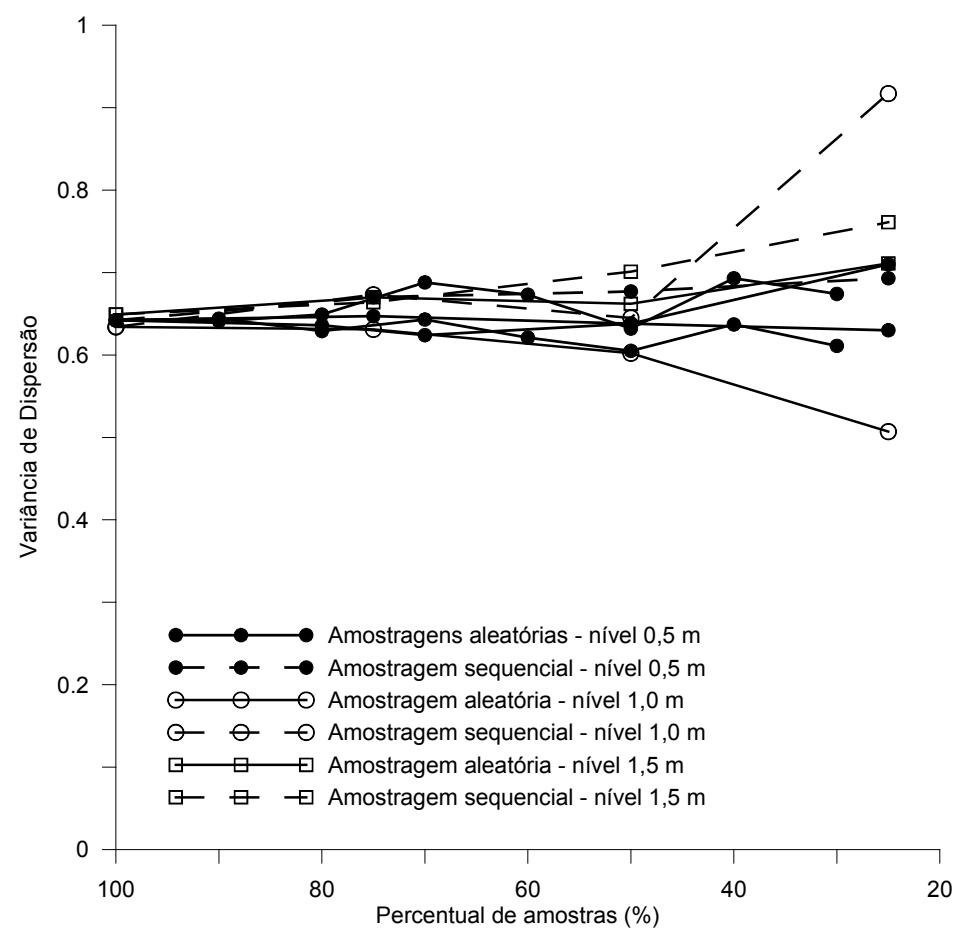

Figura 12 - Variância de dispersão dos mapas krigados 2D de concentração de VOCs. 


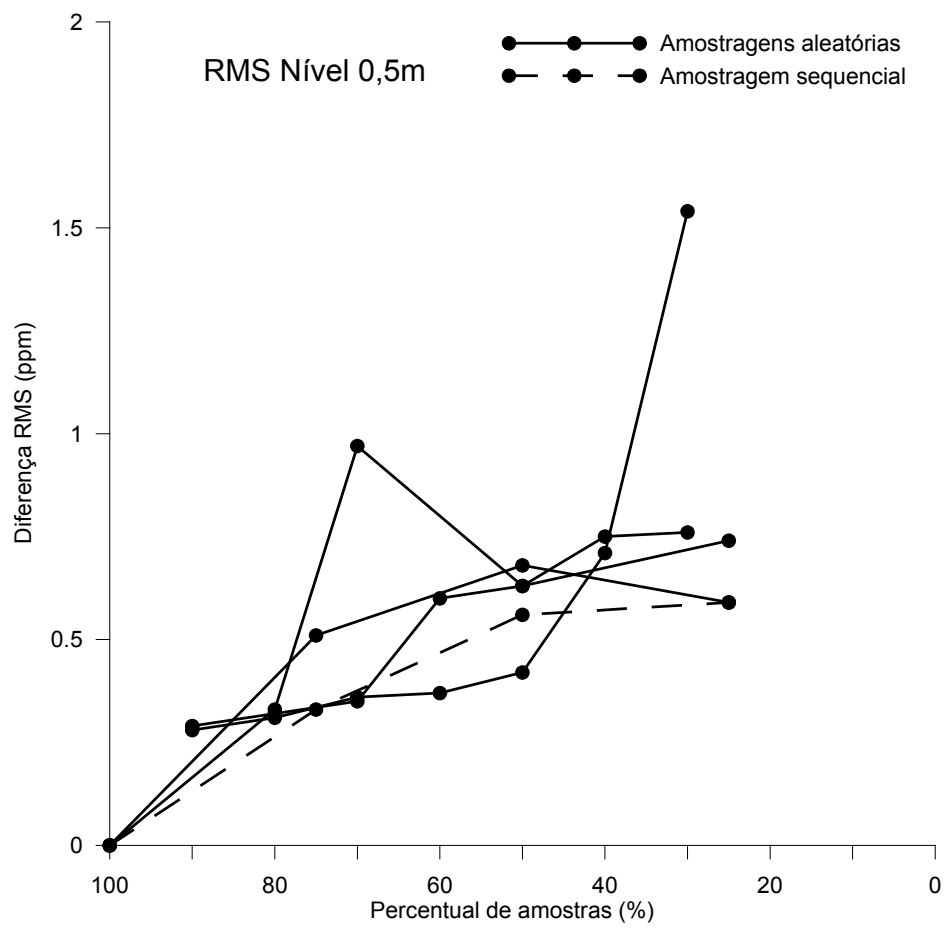

Figura 13 - Diferença RMS dos mapas 2D krigados com redução de amostras em relação ao mapa krigado com 100\% dos dados, na profundidade $0,5 \mathrm{~m}$.

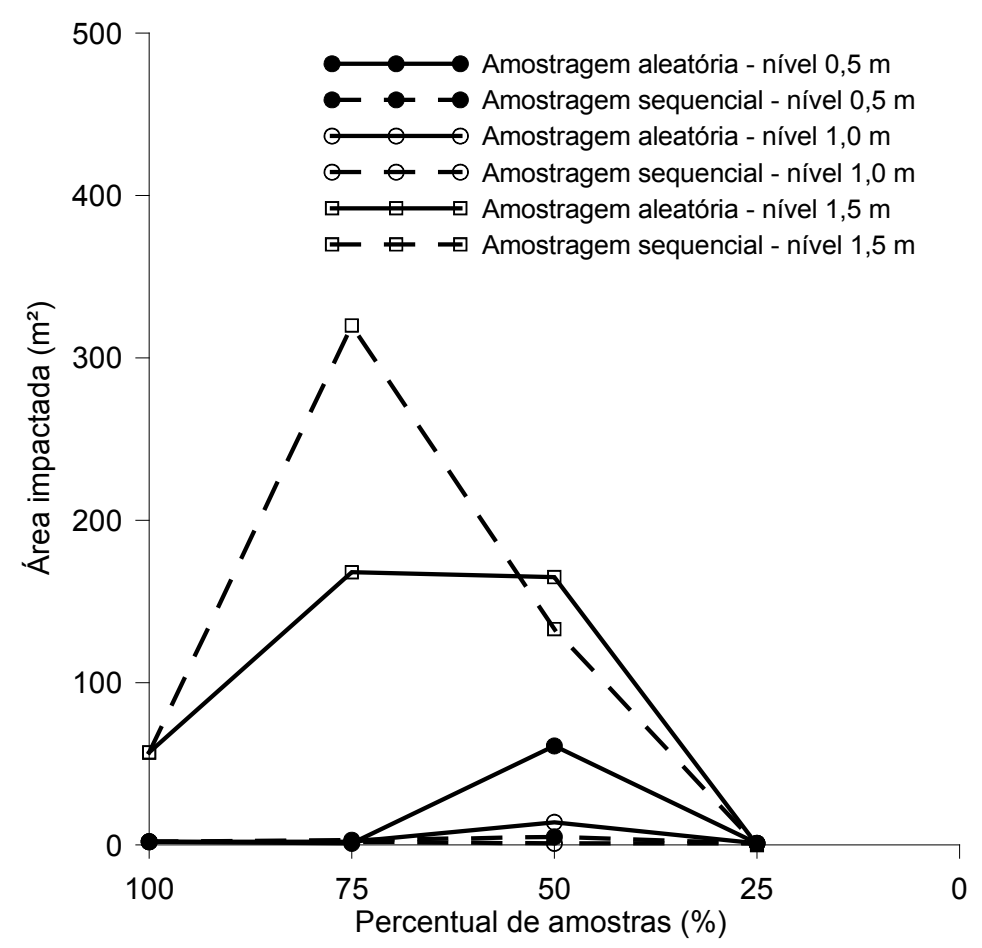

Figura 14 - Área impactada (com concentrações de VOCs acima de 20 ppm) nos mapas krigados, como função da redução no número de amostras. 


\section{CONCLUSÕES}

Foram realizadas modelagens geoestatísticas dos dados coletados usando dois métodos independentes de amostragem: aleatória e sequencial. As amostras foram coletadas em três níveis de profundidade: $0,5 \mathrm{~m}, 1,0 \mathrm{~m}$ e 1,5 m. Para o nível 0,5 m foram realizadas quatro amostragens aleatórias independentes e uma amostragem sequencial. Os resultados obtidos para as quatro amostragens aleatórias demonstraram que o comportamento observado, em termos de alcance médio, efeito pepita, variância de dispersão e diferença RMS, são aproximadamente iguais. Portanto, uma única amostragem aleatória é suficiente para representar o comportamento da distribuição espacial de VOCs com a redução no número de amostras. Os desempenhos das amostragens aleatórias e sequenciais podem ser considerados equivalentes, pois se a diferença RMS dos mapas krigados com amostragem sequencial tende a apresentar valores mínimos, estes mapas, quando amostrados com $50 \%$ dos dados, apresentam um padrão geométrico induzido pela própria distribuição espacial das amostras. Com relação aos demais parâmetros analisados ambos os tipos de amostragem apresentam resultados equivalentes.

De modo geral, os mapas krigados indicam que a contaminação se concentra principalmente na parte sul-sudoeste da área e a leste do TQ-301. Os mapas krigados apresentam um padrão de distribuição de valores de VOCs que respeita os valores amostrados. A quantificação do volume de contaminantes fica, assim, facilitada pela disponibilidade dos mapas krigados.

Em termos da variografia, o alcance médio determinado para todos os três níveis de profundidade ficou em torno de $20 \mathrm{~m}$, exceto para os casos cujo número de amostras ficou reduzido a $25 \%$ dos dados originais. Neste caso o alcance aumentou na maioria das amostragens, como esperado, e diminuiu no caso da amostragem aleatória para o nível 1,5 m.

O efeito pepita para todos os três níveis de profundidade apresentou um decréscimo suave com a redução no número de amostras, exceto para o caso da amostragem aleatória para o nível $1,0 \mathrm{~m}$ de profundidade. Isto representa a tendência de redução na aleatoriedade com a redução do número de amostras.

\section{REFERÊNCIAS BIBLIOGRÁFICAS}

ANDRIOTTI, J. L. S. Fundamentos de estatística e geoestatística. Rio Grande do Sul, Unisinos, 2003.

BOSCOV, M. E.G. Geotecnia Ambiental. São Paulo. Oficina de textos, 2008. BURROUGH, P. A. Principles of geographical information systems. Oxford University Press, New York, 1998.

CLEAN ENVIRONMENT BRASIL. Produtos e tecnologias para o meio ambiente. 1995. Disponível em:<http://www.clean.com.br/portal/ detectores-portateis-para-seguranca-do-trabalho/ gasalertmicro-5-pid>. Acesso em 15 abr. 2010.
A variância de dispersão determinada para todos os três níveis de profundidade apresentou um suave acréscimo com a redução no número de amostras, exceto para o caso da amostragem aleatória para o nível $1,0 \mathrm{~m}$ de profundidade. Isto representa o aumento da incerteza associada à redução do número de amostras.

A diferença RMS entre os mapas krigados com redução do número de amostras em relação aqueles krigados com $100 \%$ das amostras tende a aumentar com a redução do número de amostras. No entanto, a diferença RMS máxima observada foi de 2,33 ppm, quando o limite máximo considerado para não intervenção foi de 20 ppm.

O efeito da redução do número de amostras em relação à área impactada foi, em geral, muito pequeno, para ambos os métodos de amostragem, sendo sensivelmente maior para o nível de profundidade $1,5 \mathrm{~m}$. No nível mais profundo analisado $(1,5 \mathrm{~m})$ a área impactada é muito maior do que aquela observada nos níveis mais rasos, exceto para os mapas obtidos com $25 \%$ dos dados originais.

Observa-se que os mapas krigados com pelo menos $50 \%$ dos dados ainda aparentam indicar a possibilidade de redução do número de amostras, porém, quando a incidência de VOCs acima de 20 ppm está mais dispersa na área, menos de $50 \%$ dos dados pode não conseguir identificar a real distribuição de contaminantes. Considerando que os parâmetros de variografia (alcance médio, efeito pepita e variância de dispersão), a diferença RMS e a área impactada, não se alteram substancialmente com a redução no número de dados até o limite de $50 \%$, pode-se recomendar, por razões econômicas, a redução no número de amostras até esse limite. Reduções maiores que 50\% produzem mapas sensivelmente diferentes daqueles obtidos com $100 \%$ dos dados.

As principais limitações do método empregado neste trabalho são: 1) necessidade de amostras georreferenciadas, e 2) disponibilidade de um número de amostras, em relação ao espaço analisado, que resulte em uma distância média entre amostras menor ou igual ao alcance, e que se encontrem relativamente bem distribuídas no espaço. Este método pode ser aplicado na análise da distribuição espacial de qualquer variável regionalizada, não se limitando à otimização de malhas de amostragem.

$\begin{array}{ccccr}\begin{array}{c}\text { DAVIS, J. } \\ \text { terprise }\end{array} & \begin{array}{c}\text { Statistics } \\ \text { Guide. }\end{array} & \text { Using } & \text { SAS } & \text { En- } \\ & \text { Press, } & 2007 .\end{array}$ GAMMA DESIGN. GS+ for Windows Demonstration Version 5.3. Plainwell, Michigan, USA: Gamma Design Software, 2002.

GUERRA, P. A. G. Geoestatística operacional. DNPM, Distrito Federal, 1988.

JOURNEL, A.G. Geostatistics for environmental sciences. Las Vegas, Enviromental Protection Agency, 1988.

KITANIDIS, P. K. Introduction to geostatistics-Applications in hydrogeology. Cambridge University Press, 1997. 
LANDIM, P. M. B. Análise estatística de dados geológicos. 2.ed. São Paulo, Editora Unesp, 2003.

LANDIM, P. M. B.; MONTEIRO, R. C. Introdução ao GSLIB (Geostatiscal Software Library). DGA, IGCE, UNESP/Rio Claro, Lab. Geomatemática, Texto Didáti- co 01, 2000. Disponível em: http://www.rc.unesp.br/ igce/aplicada/textodi.html. Acesso em 15 Jun. 2009. YAMAMOTO, J.K. Avaliação e classificação de reservas minerais. Editora da Universidade de São Paulo, 1996. 